\title{
Performance Evaluation of a Zero-Fouling Reciprocating Scraped Surface Heat Exchanger
}

\author{
J.P. Solano ${ }^{1}$, A. García ${ }^{1}$, P.G. Vicente ${ }^{2}$ and A. Viedma ${ }^{1}$ \\ ${ }^{1}$ Dep. Ingeniería Térmica y de Fluidos. Universidad Politécnica de Cartagena, Cartagena, \\ Spain \\ ${ }^{2}$ Dep. Ingeniería de Sistemas Industriales. Universidad Miguel Hernández, Elche, Spain
}

Address correspondence to:

Dr. Juan Pedro Solano Fernández

Dep. Ingeniería Térmica y de Fluidos

Universidad Politécnica de Cartagena

Campus Muralla del Mar, 30202

Cartagena, Spain

E-mail: juanp.solano@upct.es

Phone Number: (+34) 96832 5938, Fax Number: (+34) 968325999 


\section{ABSTRACT}

An innovative self-cleaning shell and tube heat exchanger is presented. Inside each interior tube (through which the product flows) a scraping rod is fitted. This rod moves in reciprocal manner and the scraping elements mounted on the rod fully clean the tube wall surface. Additionally, the macroscopic displacements of the flow, induced by the insert device motion, promote high flow mixing. Consequently, tube-side heat transfer coefficients are enhanced.

Thermal-hydraulic and scraping power measurements are performed in laminar regime for $20<\operatorname{Re}_{h}<250$ and $0 \leq \omega \leq 1\left(\omega=u_{s c r} / u_{f}\right)$. An extended Performance Evaluation Criterion is proposed, in order to balance the augmentations of heat transfer and the increased power consumption (pumping and scraping power) of the device. This study allows stating guidelines for the operation of the device, concluding that the performance of the heat exchanger is irrespective of the velocity ratio. The scraper can be used intermittently, or at the minimum scraping frequency that ensures fouling mitigation. 


\section{INTRODUCTION}

Heat transfer processes in the food and chemical industries frequently deal with highly viscous liquids. The performance of heat exchangers working under these conditions is usually low, as a result of the characteristics of the encountered laminar regime (Webb and Kim, [1]). Moreover, the heat transfer surfaces may become coated with a deposit of solid material after a period of operation. This phenomenon, known as fouling, causes a reduced overall heat transfer coefficient (Bergles, [2]). Heat exchangers are generally over-designed to compensate for the anticipated fouling. Moreover, cleaning operations decrease equipment availability, which causes as well a considerable economic impact (Steinhagen et al., [3]).

Among the several technical solutions for fouling cleaning and prevention (MüllerSteinhagen, [4]), mechanically assisted heat exchangers, where a heat transfer surface is periodically scraped by a moving element, constitute a suitable solution for applications with severe tendency to fouling and low heat transfer rates. Dynamic heat exchangers with rotating scraping blades (SSHE) are found in commercial practice: they prevent fouling and promote mixing and heat transfer. Many investigations have focused on these anti-fouling devices, studying flow pattern characteristics (Trommelen and Beek, [5]), their thermalhydraulic performance (De Goede and De Jong, [6]) or scraping efficiency (Matsunaga et al., [7]).

This work presents an innovative scraped surface heat exchanger. This equipment is mechanically assisted by a reciprocating cylinder, that moves the scraping rods inserted in each of the interior tubes. An array of semi-circular elements is mounted on each rod, with a pitch $p=5 \mathrm{D}$. These elements fit the internal diameter of the tubes. During the reciprocating motion, they scrape the inner tube wall, avoiding fouling. 
Additionally, the movement of the inserted device generates macroscopic displacements of the flow, that continuously mix core regions with peripheral flow. As a result of the mentioned features, the reciprocating scraped surface heat exchanger provides high overall heat transfer coefficients, and prevents down time for cleaning operations.

The industrial version of this device is manufactured and market by the Spanish company HRS-Spiratube, under the commercial brand UNICUS@ Dynamic Heat Exchanger (see Fig. 1). The heat exchanger is also licensed to Alfa Laval Inc. for manufacturing, with the name Viscoline $($ Dynamic Unit. The manufacturer claims for its higher heat transfer area, smaller number of shutdowns, lower induced shear stress in the product, and particle integrity in food applications, compared to rotating scraped surface heat exchangers. This reciprocating heat exchanger is progressively being introduced in the food industry, wastewater treatment processes, production of second-generation biofuels, etc. It founds its most practical application under severe fouling tendency, where obstruction of the tubes occur in few hours if no cleaning strategies are adopted.

Depending on the severity of the fouling phenomenon, the scraper can be either activated intermittently, or move continuously in a wide range of scraping velocities. This variety of operating conditions yields to different heat transfer and pressure drop characteristics (Solano et al., [8]), as well as scraping power consumption. A characterization of the heat exchanger performance is necessary to assess the relation between heat transfer enhancement and augmentation of power consumption (pumping and scraping) in the heat exchanger, provided that tube walls keep clean in all the regimes.

To accomplish with this requirement, a thorough experimental work has been developed. Pressure drop, scraping power and heat transfer measurements are obtained in laminar regime for Reynolds numbers $20<\operatorname{Re}_{\mathrm{h}}<250$ and velocity ratios $0 \leq \omega \leq 1\left(\omega=\mathrm{u}_{\mathrm{scr}} / \mathrm{u}_{\mathrm{f}}\right)$. 
Performance Evaluation Criterion R3 (Bergles et al., [9]) has been extended to account for the scraping power consumption. This evaluation allows stating the heat exchange increase obtained when a scraper is introduced in a tubular heat exchanger, while keeping constant the heat transfer area and global power consumption. The presence of fouling in the smooth tubes of the heat exchanger has also been considered in the formulation of this criterion.

\section{EXPERIMENTAL SET-UP}

A schematic diagram of the experimental setup is shown in Fig. 2. The test section consists of a smooth tube where the scraper is inserted. A hydraulic unit provides the insert device with reciprocating motion. A secondary circuit is used for regulating the working fluid temperature. Propylene-glycol is employed as working fluid. A detail of the scraper geometry is shown in Fig. 3 and Fig. 4. It consists of lightened semicircular plugs, aimed at reducing the blockage effect experienced by the flow.

\section{Fanning friction factor}

Pressure drop tests were carried out in the hydro-dynamically developed region under isothermal conditions. Fanning friction factor were determined from fluid mass flow rate and mean pressure drop measurements by means of

$$
f_{h}=\frac{\overline{\Delta P}}{\ell_{p}} \frac{\rho \pi^{2}(D+d)^{2} D_{h}^{3}}{32 \dot{m}^{2}}
$$

Time-dependent pressure during the scraping process was measured in two sections of the tube separated by a distance $\ell_{p}=1.8 \mathrm{~m}$. Two piezorresistive pressure sensors (Kistler K-Line) 
were connected to each tube section with four pressure taps separated by $90^{\circ}$. Mean pressure drop in the tube over the scraping cycle, $\overline{\Delta P}$, was computed by integration of the instantaneous signal over 50 cycles.

\section{Scraping power}

Scraping power consumption was obtained measuring the time-dependent pressure in both chambers of the double-effect hydraulic piston, as

$\dot{W}_{\text {scr }}=\frac{\pi S\left(D_{c}^{2}-D_{p}^{2}\right)}{4} \frac{\left|\overline{\Delta P}_{p i s t o n}\right|}{\Delta t / 2}$

Two piezorresistive Kistler K-Line pressure sensors with 20 bar measuring range were employed. Scraping period $\Delta t$ was measured with a temporizer connected to final-stroke switches, that constrained the scraping amplitude to the value $\mathrm{S}=10 \mathrm{D}$.

\section{Nusselt number}

Heat transfer experiments were carried out under uniform heat flux conditions, where energy was added to the working fluid by Joule effect heating. A $6 \mathrm{kVA}$ transformer was connected to the smooth tube by copper electrodes and power supply was regulated by means of an auto-transformer. The length between electrodes defined the heat transfer test section $\left(\ell_{\mathrm{h}}=1 \mathrm{~m}\right)$. The overall electrical power added to the heating section, $\mathrm{Q}$, was calculated by measuring the voltage between electrodes $(0-15 \mathrm{~V})$ and the electrical current $(0-600 \mathrm{~A})$. 
Fluid inlet and outlet temperatures, $\mathrm{T}_{\text {in }}$ and $\mathrm{T}_{\text {out }}$ were measured by submerged type resistance temperature detectors (RTDs). Since heat was added uniformly along the tube length, the bulk temperature of the fluid at the measuring section, $\mathrm{T}_{\mathrm{b}}\left(\mathrm{x}_{\mathrm{p}}\right)$, was calculated by considering a linear variation with the axial direction. Average outside surface temperature of the wall was measured at six different axial positions along a scraper pitch, located at 30 diameters from the upstream electrode, that ensure fully developed flow. The outer wall temperature at each axial position was calculated by averaging the temperatures measured with eight surface type RTDs peripherally spaced by every $45^{\circ}$ at each axial position. Inner wall temperature $T_{w i}$ was obtained with the numerical solution of the radial, $1 \mathrm{D}$ heat conduction across the tube and insulation. The local Nusselt number is calculated by means of

$$
N u_{h, x}=\frac{D_{h}}{k} \frac{q^{\prime \prime}}{\bar{T}_{w i}-T_{b}\left(x_{p}\right)}
$$

Nusselt number results at each axial position are corrected by the factor $\left(\mu_{w} / \mu_{b}\right)^{0.14}$ to obtain correlations free of variable properties effects (Sieder and Tate, [10]). Pitch-averaged Nusselt number is obtained by averaging the six local values computed with the presented methodology.

The experimental uncertainty was calculated by following the "Guide to the expression of uncertainty in measurement", published by ISO [11]. Details of the uncertainty assignation to the experimental data are given by the authors (Vicente et al., [12]). Uncertainty calculations based on a $95 \%$ confidence level showed maximum values of $4 \%$ for Reynolds number, $4.5 \%$ for velocity ratio, $6 \%$ for Nusselt number and $8 \%$ for friction factor. 


\section{THERMAL-HYDRAULIC RESULTS}

An experimental campaign was performed to assess the thermal-hydraulic and scraping power characteristics of the device at low Reynolds number $\left(20<\operatorname{Re}_{\mathrm{h}}<250\right)$ and velocity ratios $\omega=0.1,0.5$ and 1 . Measurements with the static device $(\omega=0)$ were also performed.

\section{Pressure drop results}

Fig. 5 shows the evolution of Fanning friction factor for the above mentioned operating conditions. The insertion of a static scraper in a smooth tube yields to pressure drop increases of the order of $\Delta \mathrm{p}_{\mathrm{a}} / \Delta \mathrm{p}_{\mathrm{s}} \approx 5$ for $\mathrm{Re}_{\mathrm{h}} \approx 30$, compared to the smooth tube with same mass flow rate of product. When $\mathrm{Re}_{\mathrm{h}} \approx 250$, the pressure drop increase with respect to the smooth tube rises to $\Delta \mathrm{p}_{\mathrm{a}} / \Delta \mathrm{p}_{\mathrm{s}} \approx 10$.

The dynamic performance of the insert device is of primary importance in the course of the present study. Experimental results for $\omega=0.1$ (scraper velocity is ten times lower than fluid velocity) shows mean pressure drop increases of $20 \%$ with respect to the static performance. At velocity ratio $\omega=1$, i.e., when scraper velocity is equal to fluid velocity, head losses are $150 \%$ higher than for the static device. The comparison with the smooth tube in this working condition reveals pressure drop increases of $1000 \%$ at $\mathrm{Re}_{\mathrm{h}} \approx 30$ and $2400 \%$ at $\mathrm{Re}_{\mathrm{h}} \approx 250$. 


\section{Heat transfer results}

Heat transfer experiments were performed using propylene-glycol as working fluid, at $\mathrm{T}=15^{\circ} \mathrm{C}$, corresponding to Prandtl number $\operatorname{Pr}=700$. Results are depicted in Fig. 6 .

Nusselt number increases with Reynolds number in the laminar regime, in static and dynamic conditions. The movement of the active device yields to augmentations of the order of $15 \%$ in heat transfer at the minimum velocity ratio $(\omega=0.1)$. When the velocity ratio increases to $\omega=0.5$, heat transfer increases of $65 \%$, referenced to the static condition, are found. For the maximum velocity ratio tested, $\omega=1$, Nusselt number results are $140 \%$ higher than for $\omega=0$.

\section{Scraping power measurements}

A detail of the unsteady signal measured during a characteristic scraping cycle is shown in Fig. 7. During the co-current semi-cycle, the scraper moves in the same direction of the fluid, while in the counter-current semi-cycle, the direction of the scraper movement is contrary to the mean flow direction. During each semi-cycle, an internal valve diverts the oil at the impulse pressure to the corresponding chamber of the double-effect piston, while the other chamber drains the remaining oil towards the deposit of the hydraulic unit (discharge pressure). The pressure difference between both chambers is employed in Eq. (2) to compute the scraping power at each semi-cycle. The main forces overcome by the hydraulic piston are due to the friction between the scraping plugs and the inner tube wall. This tribological nature prevents from obtaining non-dimensional results from these experimental data.

Mean scraping power results are shown in Fig. 8 for velocity ratios $\omega=0.1,0.5$ and 1 , and flow rate ranging from 60 to $1300 \mathrm{l} / \mathrm{h}$. Scraper velocity plays a fundamental role in the scraping power consumption. For any constant velocity ratio, as flow rate increases, scraper 
velocity increases with the relation $u_{\mathrm{scr}}=\omega \times \mathrm{u}_{\mathrm{f}}$. This characteristic is observed in the higher dependence of scraping power on the flow rate for increasing velocity ratios. For flow rate $300 \mathrm{l} / \mathrm{h}$ and velocity ratio $\omega=0.1$, scraping power is $\dot{\mathrm{W}}_{\mathrm{scr}} \approx 8 \mathrm{~W}$, while for $\omega=1, \dot{\mathrm{W}}_{\mathrm{scr}} \approx 55 \mathrm{~W}$ (600\% higher).

The pumping power $\dot{W}_{p}$ (Eq. 4 ) along the scraping section, $\ell_{s c r}$, is computed as follows:

$$
\dot{W}_{p}=f_{h} \frac{\pi(D+d)}{2} \rho u_{f}^{3} \ell_{s c r}
$$

This definition allows obtaining the scraping-to-pumping power ratio, as shown in Fig. 9. This relation diminishes for increasing flow rates, which indicates the important contribution of the pressure drop in the power consumption of the dynamic heat exchanger at high flow rates.

\section{PERFORMANCE EVALUATION CRITERIA}

Previous thermal-hydraulic results show the heat transfer augmentation associated to the operation of the dynamic heat exchanger at growing velocity ratios. However, a huge increase in pressure drop and scraping power consumption also follows these working conditions.

The self-cleaning characteristic of this type of heat exchanger justifies its employment in applications with severe tendency to fouling. Nevertheless, a quantitative method is necessary to assess the benefits of the several operating conditions of the heat exchanger on its global performance. 
To cope with this necessity, Performance Evaluation Criteria, defined by Bergles et al. [9] and Webb [13], can be employed. The extension of the classical formulation to account for the increased power consumption of reciprocating scraped surface heat exchangers is proposed.

\section{Extension of Criterion R3}

Criterion R3 accounts for the heat transfer augmentation obtained when a reciprocating scraper is inserted in a smooth tube, for equal heat transfer area and power consumption. Some aspects should be pointed out:

1. The logarithmic mean temperature difference in the heat exchanger remains unchanged.

2. Shell-side heat transfer resistances and conduction through the tubes are negligible.

3. Power consumption in the smooth tube refers to pumping power.

4. Power consumption in the augmented heat exchanger is the sum of pumping power and scraping power.

According to the previous items, R3 factor can be formulated as

$$
R 3=\left(\frac{N u_{a, h}}{N u_{s}} \frac{D}{D_{h}}\right)_{N, \ell, \dot{W}, \Delta T}
$$


Eq. 5 relates the heat transfer coefficient in the tube side of the reciprocating scraped surface heat exchanger with the heat transfer coefficient in the equivalent smooth pipe. However, a further extension of this formulation can be done if the existence of a fouling resistance $\left(\mathrm{R}_{\mathrm{f}}\right)$ in the smooth tube is considered:

$\frac{1}{U_{s} A_{e}}=\frac{1}{h_{s} A_{i}}+\frac{R_{f}}{A_{i}}$

Being R3 $=\mathrm{U}_{\mathrm{a}} / \mathrm{U}_{\mathrm{s}}$, substitution of Eq. 6 yields:

$$
R 3=\frac{N u_{a, h}}{N u_{s}}\left(\frac{D+N u_{s} R_{f} k}{D_{h}}\right)_{N, \ell, W, \Delta T}
$$

In Eqs. (5) and (7), $\mathrm{Nu}_{\mathrm{s}}$ is the Nusselt number in the smooth pipe evaluated at the equivalent Reynolds number $\mathrm{Re}_{\mathrm{s}}$, which is subjected to the constraint of equal power consumption in both smooth and augmented tubes:

$$
\operatorname{Re}_{s}^{3}=\frac{1}{f_{s}}\left(\operatorname{Re}_{a, h}{ }^{3} f_{a, h} \frac{D^{2}(D+d)}{D_{h}{ }^{3}} \ell_{s c r}+\frac{2}{\pi} \frac{\rho^{2} D^{2}}{\mu^{3} \ell_{s c r}} \dot{W}_{s c r}\right)
$$


Considering the thermal entry effects observed within high Prandtl flows, Pethukov and Polyakov [14] correlation will be employed for $\mathrm{Re}_{\mathrm{s}}<2300$. It allows computing smooth tube mean Nusselt number in laminar regime, as a function of non-dimensional length $\mathrm{x}^{*}$ :

$N u_{s}=4.36+1.31\left(x^{*}\right)^{1 / 3} e^{-13 \sqrt{x^{*}}}$

In turbulent regime, the correlation proposed by Gnielinski [15] is employed, relating Nusselt number with Reynolds number and Prandtl number:

$N u_{s}=\frac{\left(f_{s} / 2\right)(\operatorname{Re}-1000) P r}{1+12.7 \sqrt{f_{s} / 2}\left(\operatorname{Pr}^{2 / 3}-1\right)}$

A graphical representation of Eqs. (9) and (10) is depicted in Fig. 10.

\section{Results and discussion}

R3 extended criterion has been computed with Eqs. (5) and (7). The graphical representation is shown in Fig. 11.

Results obtained with Eq. (5) relate heat transfer in the augmented geometry with heat transfer in a clean smooth tube. Augmentations of heat transfer between 2 and 5 times are found when the scraper works as static insert device. 
In dynamic conditions, the device yields to enhanced performance (R3>1) for $\operatorname{Re}_{s}>400$. Maximum augmentations in heat transfer of 2.5 times are found for $\operatorname{Re}_{\mathrm{s}} \approx 2000$. The results are irrespective of the velocity ratio. This behavior highlights the counteracting effect of the increased pumping and scraping power on the heat transfer enhancement. Furthermore, the better performance shown in static conditions confirms the dramatic effect of scraping power, especially at low Reynolds number.

A fouling resistance $\mathrm{R}_{\mathrm{f}}=2.5 \cdot 10^{-3} \mathrm{~m}^{2} \mathrm{~K} / \mathrm{W}$ is considered for the smooth tubes in Eq. (7), according to the experimental results of Chen et al. [16] for milk fouling. In this case, R3 factor is around $85 \%$ higher than the previous results. It allows stating the combined utility of the reciprocating scraper as heat transfer promoter due to mixing and fouling mitigation. Under these conditions, maximum heat transfer augmentations R3=5 are found in dynamic conditions.

The poor differences in performance of the device for different velocity ratios entail that the associated heat transfer enhancement is counteracted by the unacceptable pressure drop and scraping power increase. Thus, it is recommended to activate the scraper intermittently for cleaning operations. In this case, the scraper will act as a static mixer during most of the operating time, enhancing heat transfer, while power consumption of the equipment is minimized. If fouling conditions are severe, the scraper should work in continuous regime at the minimum frequency that ensures fouling mitigation. 


\section{CONCLUSIONS}

1. Thermal-hydraulic and scraping power measurements have been performed in an innovative reciprocating scraped surface heat exchanger, for a wide range of working conditions.

2. Maximum augmentations of pressure drop of $150 \%$ have been found when the scraper moves with velocity ratio $\omega=1$, with respect to the static conditions. Heat transfer augments $140 \%$ in this operating range. Scraping power shows a strong dependency on scraper velocity.

3. A new formulation of R3 criterion, that accounts for the scraping power, has been proposed. The comparison with a fouled smooth tube has also been stated.

4. Heat transfer augmentations up to 5 times are found for the static device, according to $\mathrm{R} 3$ criterion. If compared to the fouled smooth tube, this factor arises to 8 , for laminar regime.

5. The performance of the dynamic device is irrespective of the velocity ratio, and lower in every working conditions than the static results. Thus, the scraper should work intermittently, for cleaning operations, or continuously with the minimum scraping frequency, to minimize power consumption.

\section{NOMENCLATURE}

$c_{\mathrm{p}} \quad$ specific heat $\left(\mathrm{J} \mathrm{kg}^{-1} \mathrm{~K}^{-1}\right)$

D tube inner diameter $(\mathrm{m})$

$\mathrm{D}_{\mathrm{h}} \quad$ hydraulic diameter (m)

$\mathrm{D}_{\mathrm{c}}$ piston chamber diameter (m) 
$\mathrm{D}_{\mathrm{p}}$ piston diameter $(\mathrm{m})$

d rod diameter (minimum inner) (m)

$\mathrm{f}_{\mathrm{h}} \quad$ Fanning friction factor, $\Delta \mathrm{P} \mathrm{D} \mathrm{D}_{\mathrm{h}} /\left(2 \rho \mathrm{u}_{\mathrm{f}}^{2} 1_{\mathrm{p}}\right)[-]$

$\mathrm{h} \quad$ heat transfer coefficient $\left(\mathrm{W} \mathrm{m}^{-2} \mathrm{~K}^{-1}\right)$

$\mathrm{k} \quad$ thermal conductivity $\left(\mathrm{W} \mathrm{m}^{-1} \mathrm{~K}^{-1}\right)$

$\ell_{\mathrm{p}} \quad$ length between pressure taps (m)

$\ell_{\mathrm{h}} \quad$ length of the heat transfer section (m)

$\ell_{\text {scr }} \quad$ length of the scraper (m)

$\dot{m} \quad$ mass flow rate $\left(\mathrm{kg} \mathrm{s}^{-1}\right)$

$\mathrm{Nu}_{\mathrm{h}}$ Nusselt number, $\mathrm{hD}_{\mathrm{h}} / \mathrm{k}[-]$

$\mathrm{p} \quad$ pitch of the insert devices (m)

$\overline{\Delta P}$ time averaged pressure drop $(\mathrm{Pa})$

Pr Prandtl number, $\mu \mathrm{c}_{\mathrm{p}} / \mathrm{k}[-]$

Q overall electrical power added (W)

Q1 heat losses in the test section (W)

q" heat flux $\left(\mathrm{W} \mathrm{m}^{-2}\right)$

$\mathrm{Re}_{\mathrm{h}} \quad$ Reynolds number, $\rho \mathrm{u}_{\mathrm{f}} \mathrm{D}_{\mathrm{h}} / \mu[-]$

S $\quad$ scraping amplitude (m)

$\Delta t$ scraping period (s) 
$\mathrm{T}$ temperature $(\mathrm{K})$

$\mathrm{u}_{\mathrm{f}} \quad$ mean fluid velocity, $(\mathrm{m} / \mathrm{s})$

$\mathrm{u}_{\mathrm{scr}} \quad$ mean scraping velocity, $(\mathrm{m} / \mathrm{s})$

$\dot{\mathrm{W}}_{\text {scr }}$ scraping power $(\mathrm{W})$

$\dot{\mathrm{W}}_{\mathrm{p}} \quad$ pumping power $(\mathrm{W})$

$\mathrm{x}_{\mathrm{p}} \quad$ measuring point axial position (m)

$\mathrm{x}^{*} \quad$ non-dimensional length, $\mathrm{x} /(\mathrm{D} \cdot \mathrm{Re} \cdot \mathrm{Pr})[-]$

$\omega \quad$ velocity ratio, $\mathrm{u}_{\mathrm{scr}} / \mathrm{u}_{\mathrm{f}}[-]$

$\rho \quad$ fluid density $\left(\mathrm{kg} \mathrm{m}^{3}\right)$

$\mu \quad$ fluid viscosity $\left(\mathrm{kg} \mathrm{m}^{-1} \mathrm{~s}^{-1}\right)$

\section{Subscripts}

b based on bulk temperature

scr scraper

f fluid

c hydraulic chamber

in tube inlet

out tube outlet

w based on inside wall temperature 


\section{REFERENCES}

[1] Webb, R.L., and Kim, N., Principles of Enhanced Heat Transfer, $2^{\text {nd }}$ ed., Taylor and Francis, New York, USA, 2005.

[2] Bergles, A.E., ExHFT for fourth generation heat transfer technology, Experimental Thermal and Fluid Science, Vol. 26, pp. 335-344, 2002.

[3] Steinhagen, R., Müller-Steinhagen, H., and Maani, K., Problems and costs due to heat exchanger fouling in New Zealand industries, Heat Transfer Engineering, Vol. 14, pp. 19-30, 1992.

[4] Müller-Steinhagen, H., Handbook of Heat Exchanger Fouling - Mitigation and Cleaning Technologies, Publico Publications, 2000.

[5] Trommelen, A.M., and Beek, W.J., Flow phenomena in a scraped surface heat exchanger, Chemical Engineering Science, Vol. 26, pp. 1933-1941, 1971.

[6] De Goede, R., and De Jong, E.J., Heat transfer properties of a scraped-surface heat exchanger in the turbulent flow regime, Chemical Engineering Science, Vol. 48, No. 8, pp.1393-1404, 1993.

[7] Matsunaga, T., Roh, M. and Kamota, T., Heat transfer and power consumption in a scraped surface heat exchanger, International Institute of Refrigeration, Washington D.C., USA, 2003.

[8] Solano, J.P., García, A., Vicente, P.G., and Viedma, A., Experimental study of heat transfer and pressure drop in mechanically-assisted heat exchangers with active scrapers, Proc. $13^{\text {th }}$ Int. Heat Transfer Conference, Sydney, Australia, 2006. 
[9] Bergles, A.E., Blumenkrantz, A.R., and Taborek, J., Performance evaluation criteria for enhanced heat transfer surfaces, Journal of Heat Transfer, Vol. 2, pp. 239-243, 1974.

[10] Sieder, E.N., and Tate, E.G., Heat transfer and pressure drop of liquids in tubes, Ind. Eng. Chem., Vol. 28, p. 1429. 1936.

[11] ISO, Guide to the Expression of Uncertainty in Measurement, first ed., International Organization for Standardization, Switzerland, 1995.

[12] Vicente, P.G., García, A., and Viedma, A., Experimental study of mixed convection and pressure drop in helically dimpled tubes for laminar and transition flow, International Journal of Heat and Mass Transfer, Vol. 45, pp. 5091-5105, 2002.

[13] Webb, R.L., Performance evaluation criteria for used of enhanced heat transfer surfaces in heat exchanger design, International Journal of Heat and Mass Transfer, Vol. 24, pp. 715-726, 1981.

[14] Petukhov, B.S., and Polyakov, A.F., Heat Transfer in Turbulent Mixed Convection, $1^{\text {st }}$ ed., Hemisphere Publishing, New York, USA, 1998.

[15] Gnielinski, V., New equations for heat and mass transfer in turbulent pipe and channel flow, International Chemical Engineering, Vol. 16, pp. 359-368, 1976.

[16] Chen, X.D., Li, D.X.Y., Lin, S.X.Q., and Özkan, N., On-line fouling/cleaning detection by measuring electric resistance- equipment development and application to milk fouling detection and chemical cleaning monitoring, Journal of Food Engineering, Vol. 61, pp. 181-189, 2003. 


\section{List of figure captions}

Fig. 1 UNICUS $^{\odot}$ Dynamic Heat Exchanger. Courtesy of HRS-Spiratube, S.L.

Fig. 2 Experimental facility for thermal-hydraulic and power consumption measurements

Fig. 3. Sketch of the reciprocating scraper

Fig. 4. Geometry of the scraping plug

Fig. 5. Fanning friction factor results for static and dynamic conditions. Comparison with equivalent smooth pipe

Fig. 6. Nusselt number results

Fig. 7 Pressure signal in both piston chambers, during a characteristics scraping cycle

Fig. 8. Scraping power measurements

Fig. 9. Scraping-to-pumping power ratio

Fig. 10 Nusselt number in a smooth pipe, with correlations of Pethukov and Polyakov (laminar) and Gnielinski (turbulent)

Fig. 11. R3 extended performance evaluation factor. Comparison with clean smooth tubes (black) and fouled smooth tubes (red) 


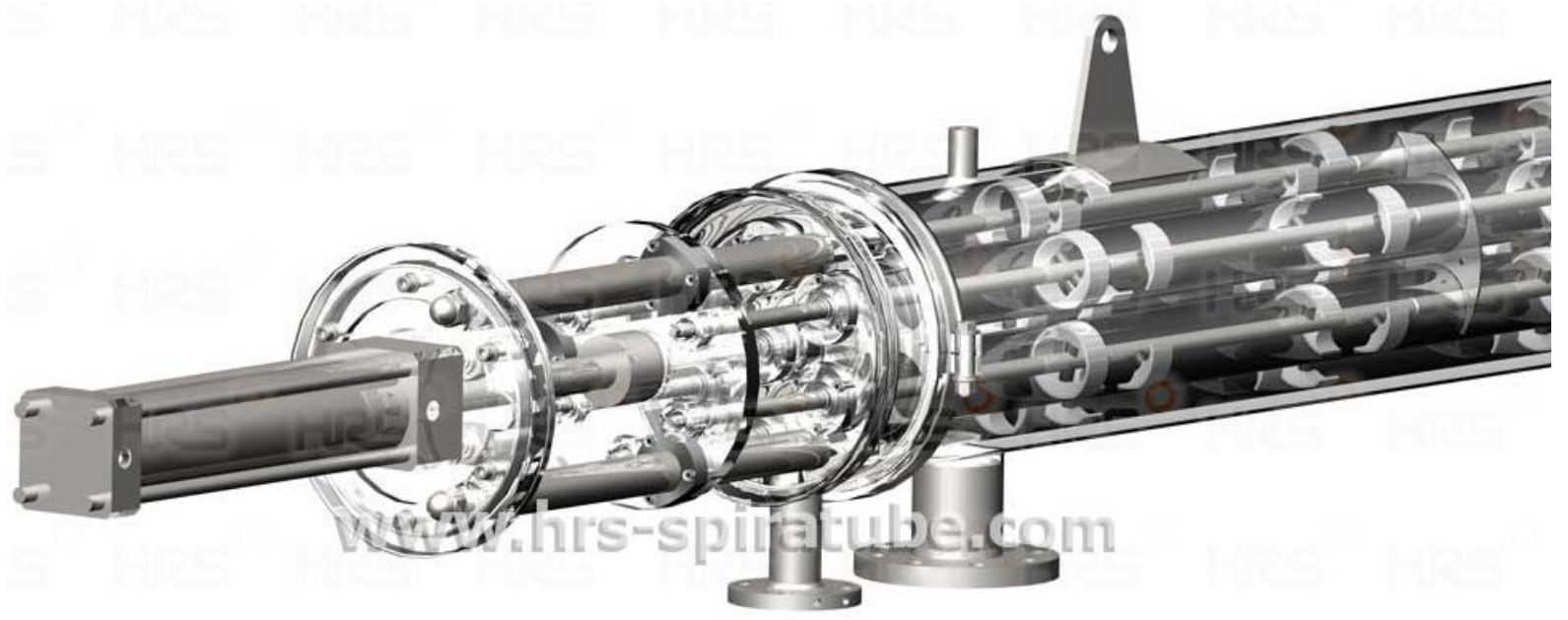

Fig. 1 UNICUS ${ }^{\odot}$ Dynamic Heat Exchanger. Courtesy of HRS-Spiratube, S.L. 


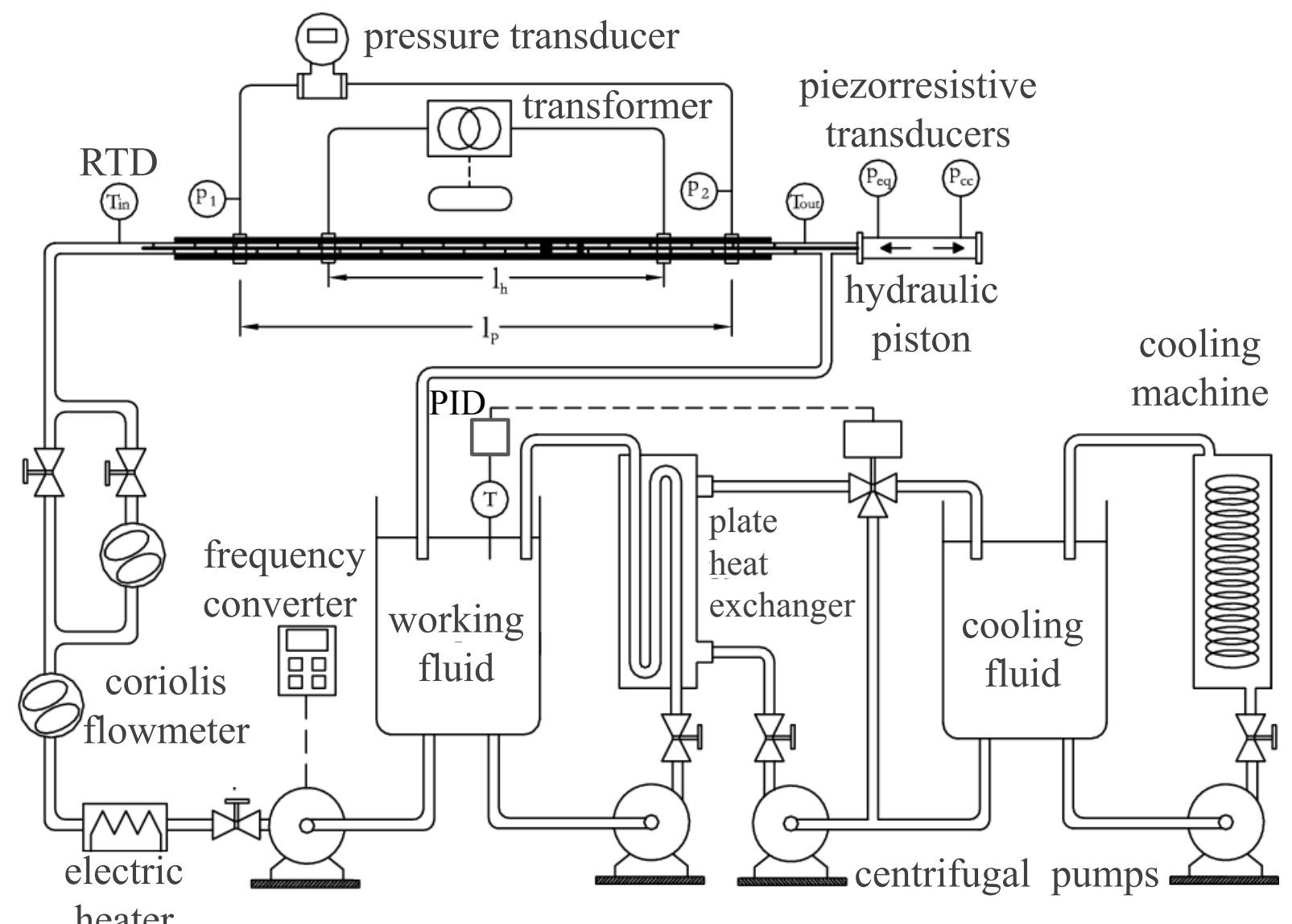

Fig. 2 Experimental facility for thermal-hydraulic and power consumption measurements 


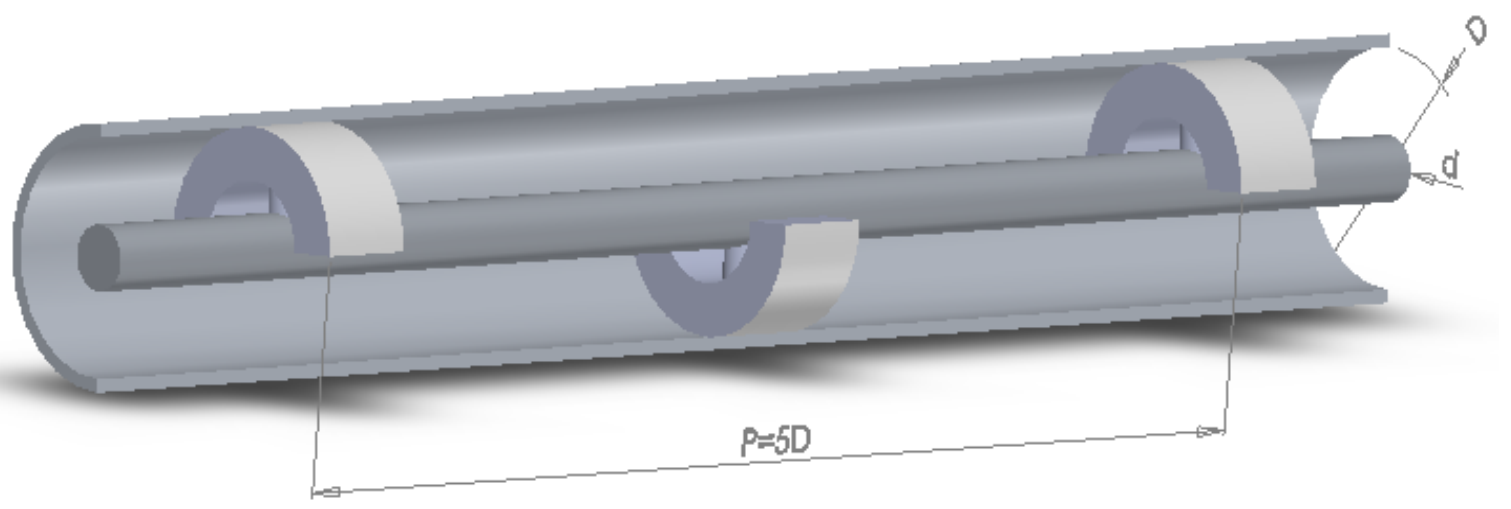

Fig. 3. Sketch of the reciprocating scraper 


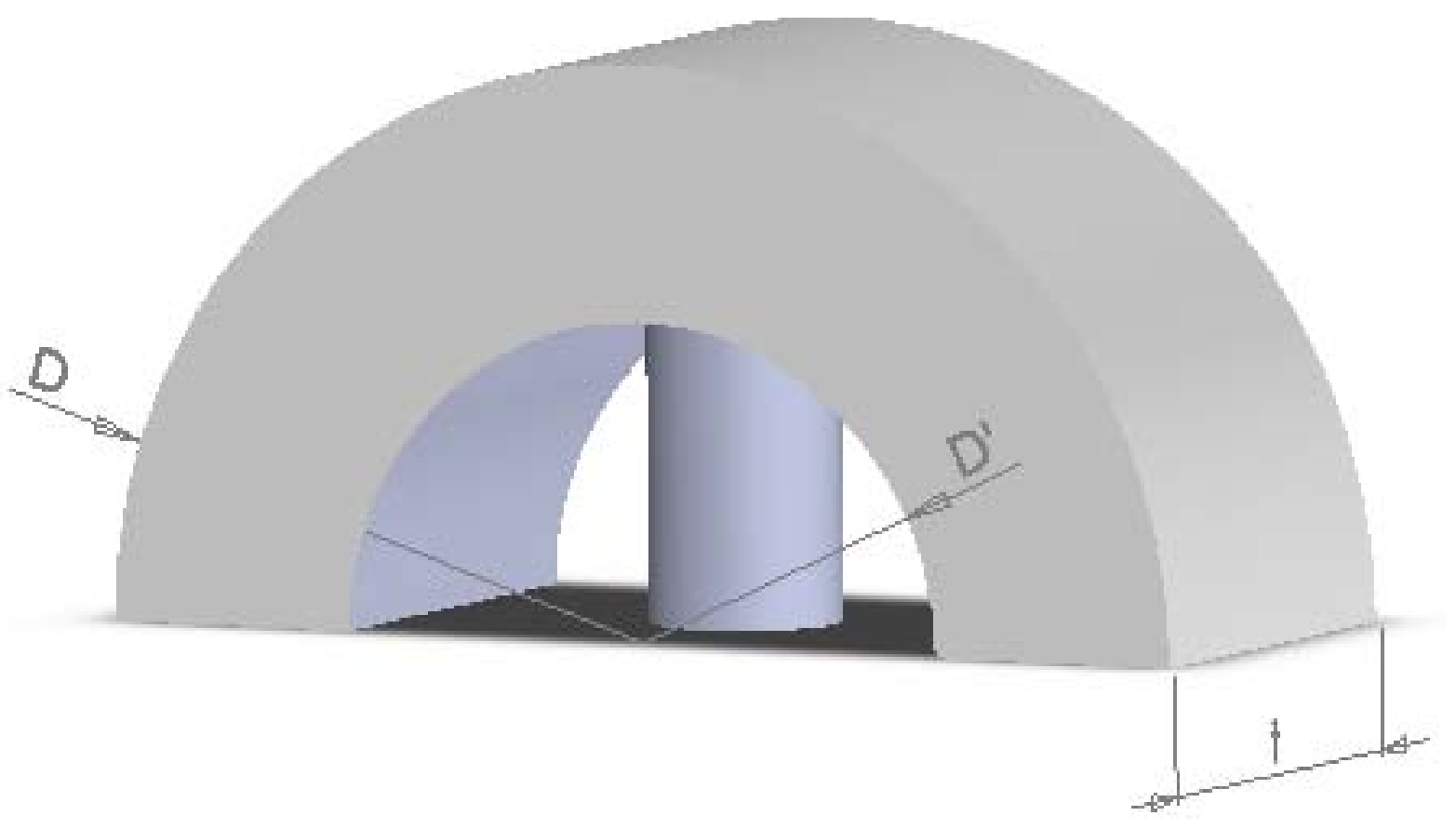

Fig. 4. Geometry of the scraping plug 


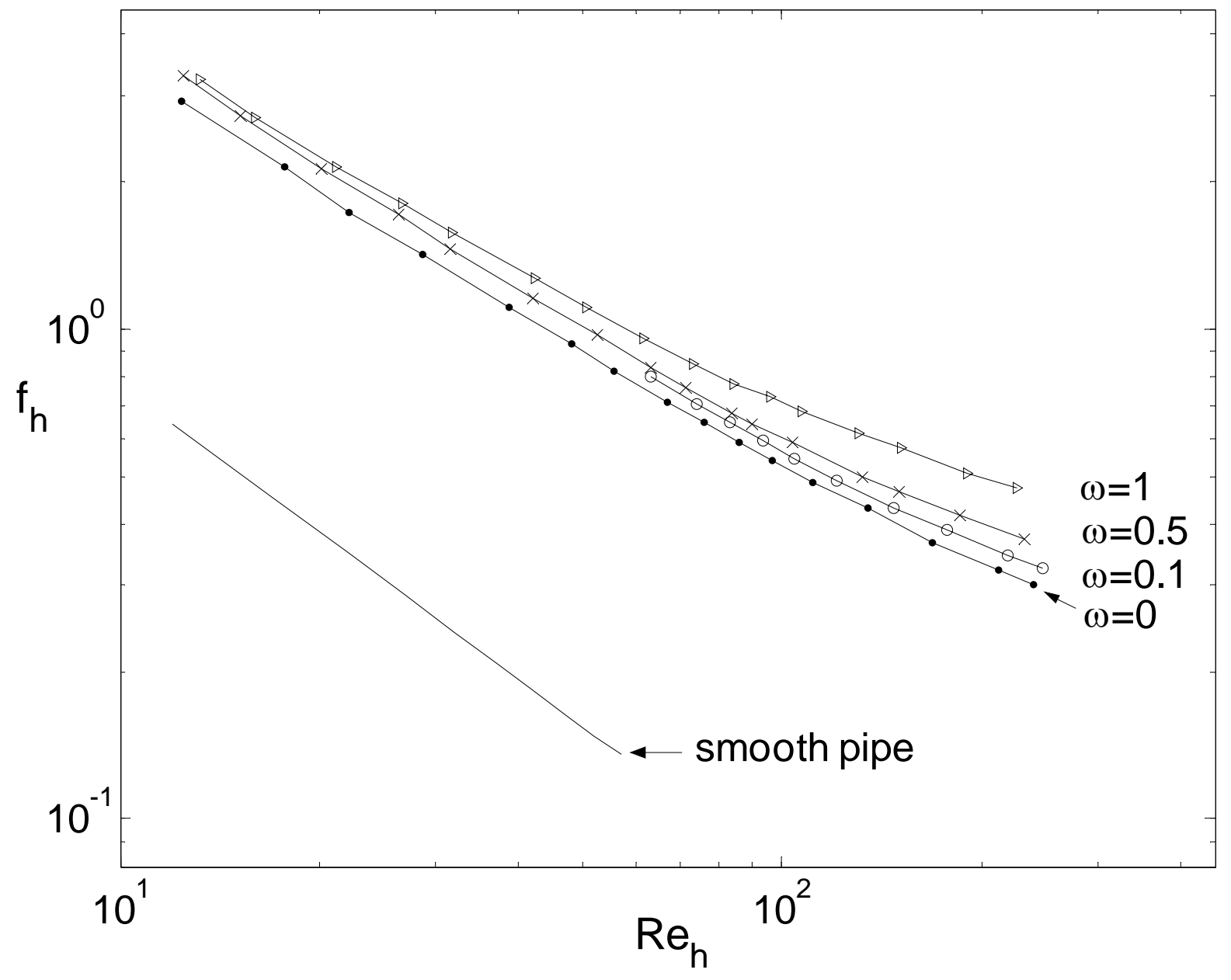

Fig. 5. Fanning friction factor results for static and dynamic conditions. Comparison with equivalent smooth pipe 


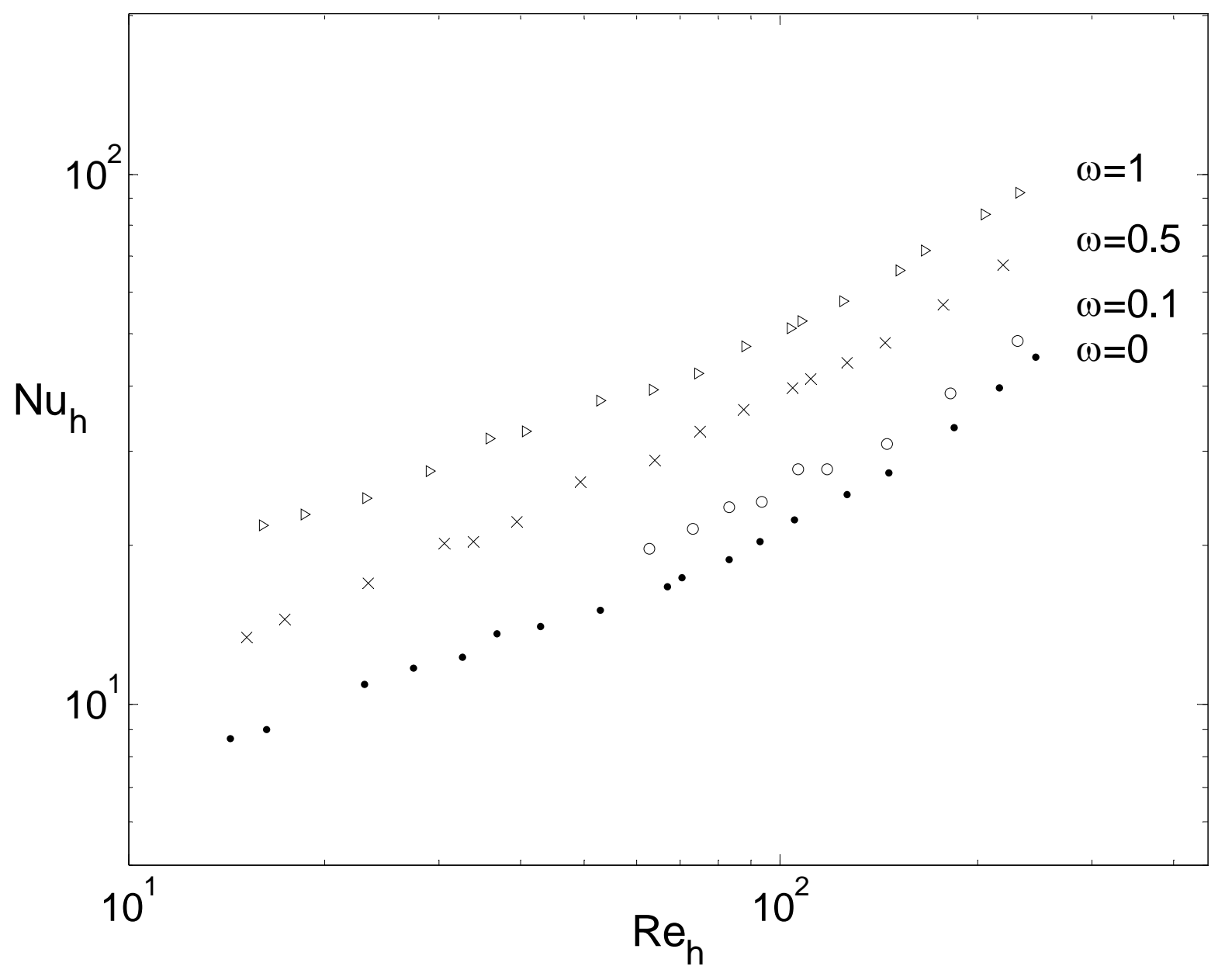

Fig. 6. Nusselt number results 


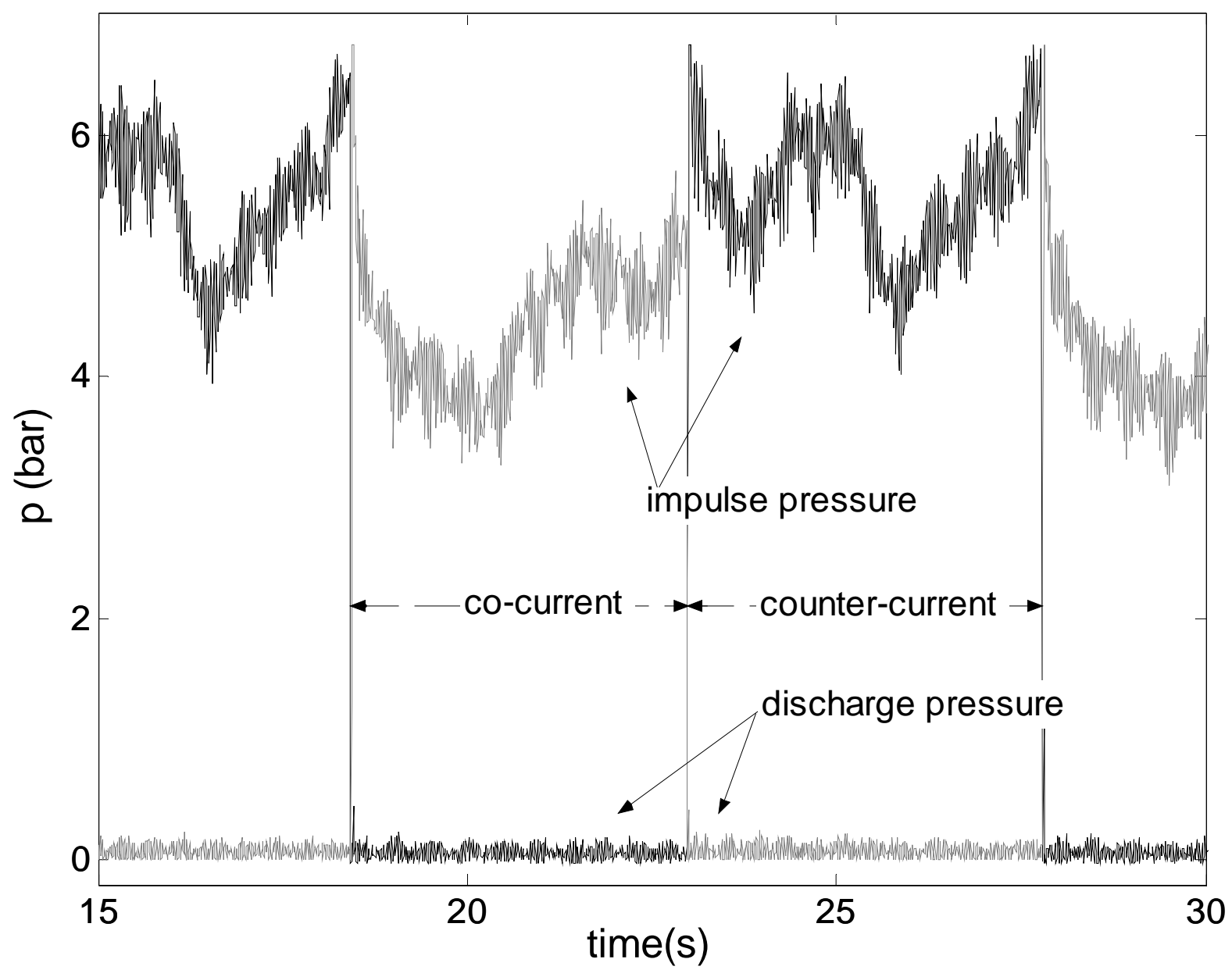

Fig. 7 Pressure signal in both piston chambers, during a characteristics scraping cycle 


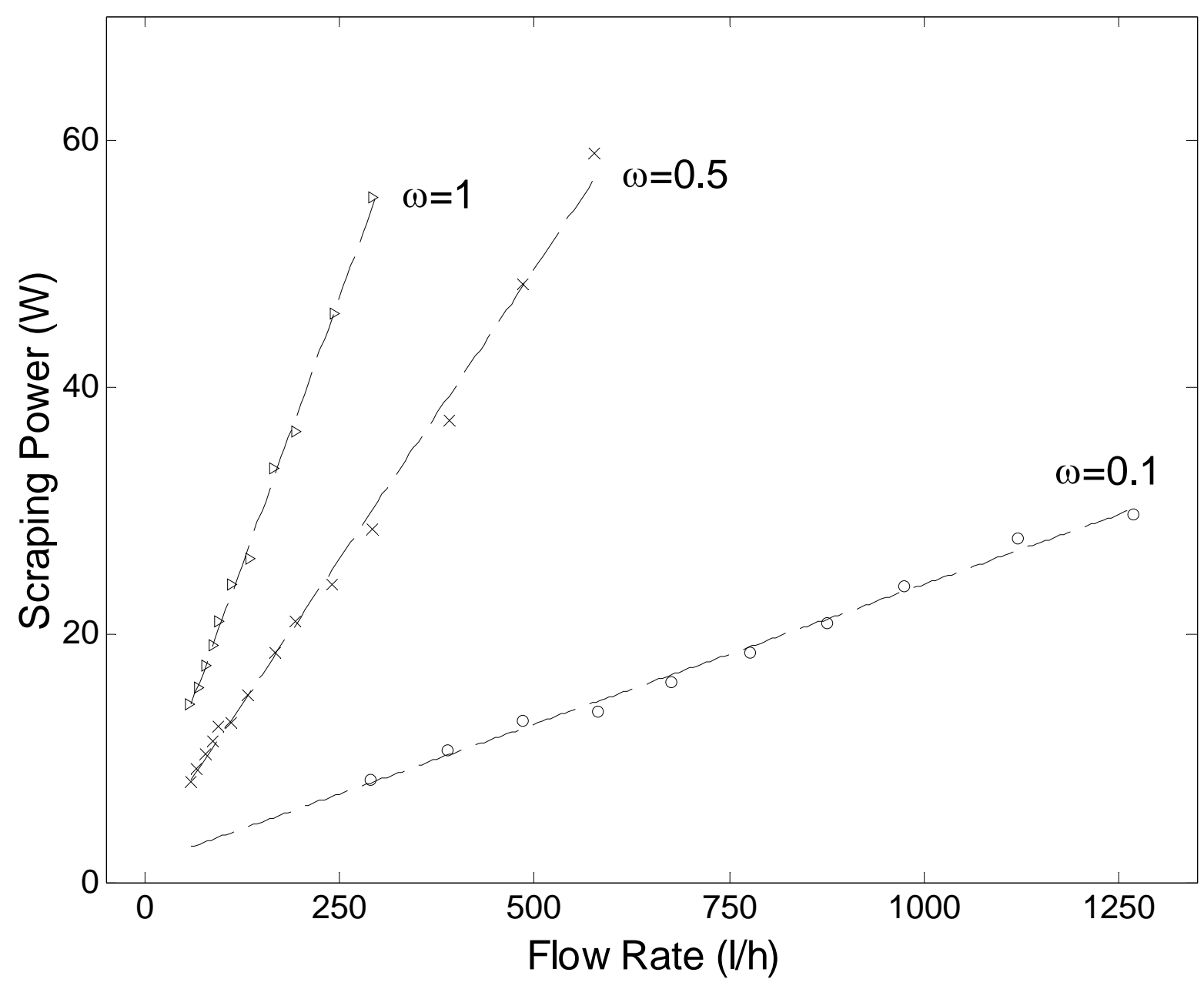

Fig. 8. Scraping power measurements 


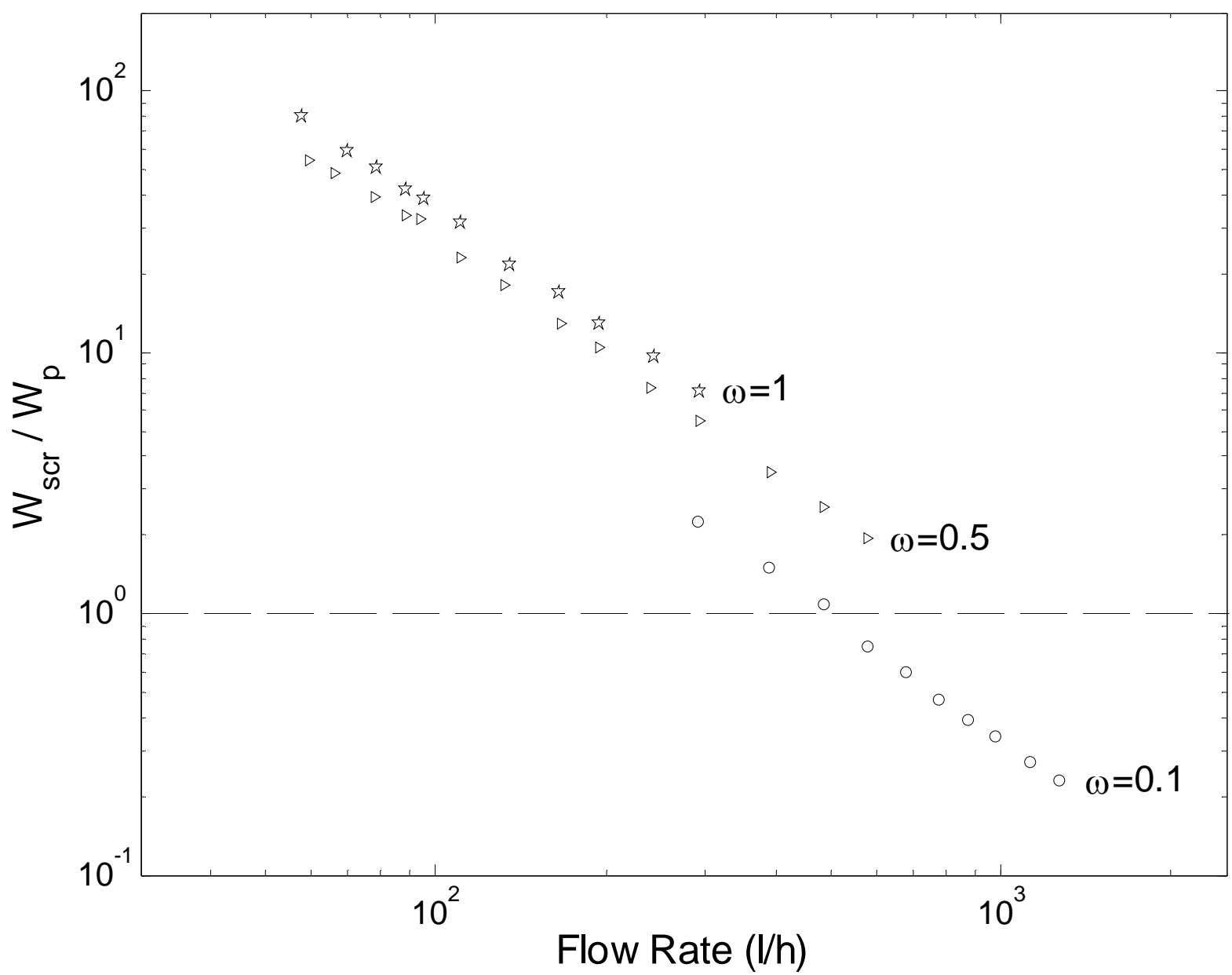

Fig. 9. Scraping-to-pumping power ratio 


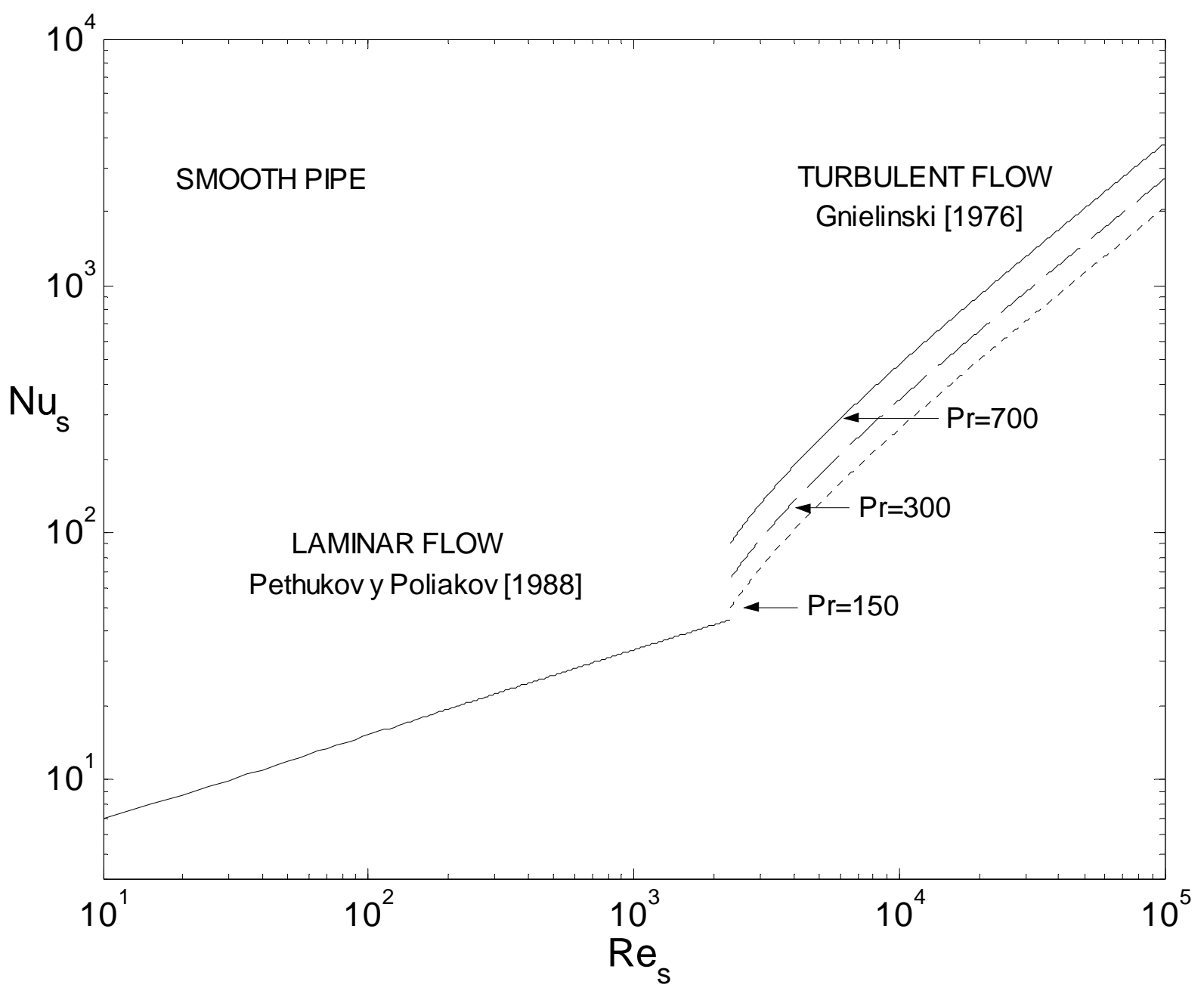

Fig. 10 Nusselt number in a smooth pipe, with correlations of Pethukov and Polyakov (laminar) and Gnielinski (turbulent) 


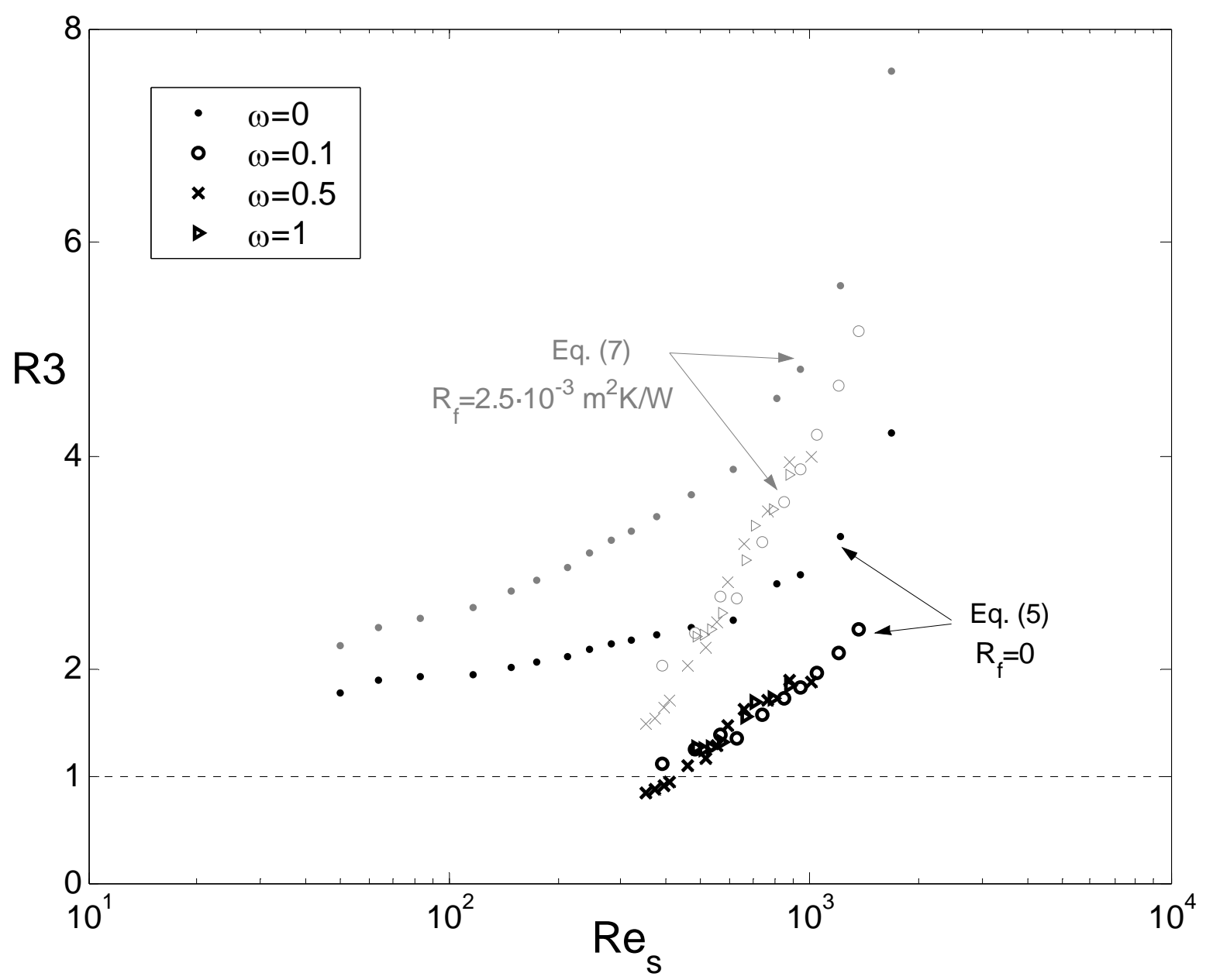

Fig. 11. R3 extended performance evaluation factor. Comparison with clean smooth tubes (black) and fouled smooth tubes (red) 

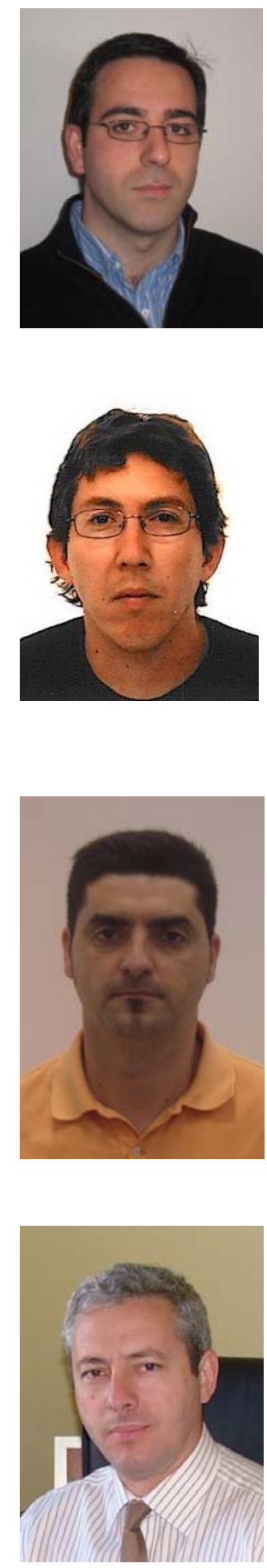

Juan Pedro Solano is Assistant Professor at Universidad Politécnica de Cartagena (UPCT) in Spain. He graduated in Mechanical Engineering in 2002 at the same university, and post-graduated in Fluid Mechanics in 2004 at von Karman Institute (Belgium). He obtained his PhD from UPCT in 2009. His main research interests are heat transfer enhancement in industrial heat exchangers, and external heat transfer in gas turbines.

\begin{abstract}
Alberto García is Associate Professor at Universidad Politécnica de Cartagena (UPCT) in Spain. He received the degree of Mechanical Engineer at the Universidad Politécnica de Valencia (UPV), Spain, in 1999, and obtained his $\mathrm{PhD}$ from UPCT in 2006. His research interests include heat transfer enhancement in industrial heat exchangers, and enhancement of Solar-thermal energy systems.
\end{abstract}

Pedro G. Vicente is currently Professor of Heat Transfer and Thermodynamics at Universidad Miguel Hernandez (UMH) in Spain. He graduated in Mechanical Engineering in 1997 at Universidad Politécnica de Cartagena and the Ph.D. at the same University in 2002. His main research interests are heat transfer enhancement in industrial heat exchangers, and solar energy for thermal applications.

Antonio Viedma is currently Professor of Fluid Mechanics at Universidad Politécnica de Cartagena (UPCT), Spain. He received the degree of Aeronautical Engineer at the Universidad Politécnica de Madrid (UPM), Spain, in 1983 and the Ph.D. at the same University in 1988. He has been formerly the head of the Department of Thermal and Fluids Engineering, and Vice-rector of the UPCT. His research contributions have been mainly in experimental Fluid Dynamics and Heat Transfer, leading an active research group since his arrival to Cartagena in 1994. He has also performed applied research under contract for aeronautical and industrial companies, and has taught Aerodynamics and Flight Mechanics at the Academia General del Aire (Spanish Air Force Academy). 